\title{
CORDEL DE MEMÓRIAS DE FRANCISCO CATARINO: VERDADEIRO GRAPIÚNA ${ }^{1}$
}

\section{Marcos Roberto de Santana*}

RESUMO: O presente representa um esforço intelectual no sentido de dar visibilidade ao relato autobiográfico do cidadão Francisco Catarino Alves de Souza, nascido no município de Ilhéus em 09 de março de 1901, às margens do Rio Almada. O manuscrito deixado por ele vem à lume após permanecer cinco décadas no mais completo anonimato. Um criterioso processo de leitura, transcrição e reescrita daria ensejo à uma possível publicação. Por outro lado, a plena consciência de cidadania teria inspirado o autor a se identificasse no texto como "verdadeiro grapiúna" e essa autoafirmação identitária serviu de fio condutor para o desenvolvimento do referido artigo em diálogo com outras vozes literárias que naturalmente representam a região sul da Bahia.

PALAVRAS-CHAVE: Autobiografia; Cordel; Memória; Literatura.

\footnotetext{
${ }^{1}$ Manuscrito inédito, representa um dos raríssimos relatos autobiográficos já conhecidos na região Sul da Bahia. Teria sido elaborado com o firme propósito de ser transmitido aos descendentes e demais familiares.

* Mestre em Linguagens pela Universidade do Estado da Bahia (Uneb).
} 


\section{Introdução}

Em Almada o Itaípe se traveste

Ao embalar-se pelo vale verdeja E de vermelho foi salpicado pelo sangue

De Pedro Hollenwerger pioneiro

Da derrama de cacau na região (SALES, 1981a, p. 29).

Falar do município de Ilhéus tem sido uma atividade intelectual e acadêmica cujo maior prestígio tem sido atribuído a alguns autores que se revezam década após década nessa tarefa, sobretudo, a partir da segunda metade do século XX. O que se observa, no entanto, entre a infinidade de publicações disponíveis é uma repetição quase que obrigatória de aspectos históricos, políticos e sociais (Cf. BRANDÃO; ROSÁRIO, 1970; BARROS, 2004; SALES, 1981). Na maioria dos casos prevalece a narrativa de afirmação de valores de quem esteve ou de quem está no poder seja na esfera política, econômica ou religiosa (Cf. HEINE, 2003; SOUB, 2005). O discurso implícito em alguns livros consultados e a quase necessária reprodução de fotografias procuram legitimar a voz e a imagem das autoridades que definiram e ainda definem os destinos da uma municipalidade que desde sempre se mostrou rica e diversificada em seus extratos sociais. Um olhar crítico e mais abrangente pode identificar a existência de uma paisagem local formada por diversas etnias e por culturas que se definem na atualidade pela relação de simbiose que teriam estabelecido no passado. Portanto, falar do município de Ilhéus não deve ser uma tarefa muito fácil sem o necessário exercício intelectual alongado em criatividade, afim de não incorrer em abordagens que podem se resumir em repetição de dados cronológicos e na legitimação do status quo de grupos dominantes.

Partimos da premissa que algumas vozes teriam sido silenciadas ou mesmo nunca tiveram espaço para ecoarem os anseios de também poderem ocupar um lugar de prestígio social. Nesse contexto de reivindicação de espaço no âmbito acadêmico é que começa a se estabelecer o diálogo com as vozes que representam as minorias sociais, que atuaram e ainda atuam em instâncias de micro poder em Ilhéus, quer desempenhado protagonismo 
comunitário como lideranças reconhecidas e legitimadas, quer na produção de cultura literária com a eloquência inata de romanceiros e cantadores medievais.

Em 1972, o então diretor do IPAC, Vivaldo da Costa Lima esteve à frente de um projeto institucional que tinha o objetivo de compreender as transformações sociais que teriam ocorrido na região do chamado Pelourinho, perímetro do Centro Antigo de Salvador que serviu de inspiração ao escritor Jorge Amado, sobretudo na elaboração do romance Tenda dos milagres (1969). O protagonista Pedro Archanjo, bedel da Faculdade de Medicina teve Miguel Archanjo de Santana como principal fonte de referência biográfica para o autor. Miguel, embora de origem mestiça, foi homem rico e respeitado na Cidade da Bahia e o famoso escritor grapiúna teria sido seu discípulo no Candomblé de São Gonçalo. Ao que se sabe, o Obá Aré Miguel Santana nunca teve a intensão de escrever suas memórias, mas encontrou muita gente interessada na sua história de vida e na sua narrativa afro-baiana ${ }^{2}$. Boa prosa e detentor de conhecimentos ancestrais de matrizes culturais afro-brasileiras, Santana foi alvo de interesse do antropólogo Vivaldo da Costa Lima e do já consagrado romancista Jorge Amado. Nesse contexto é que Miguel, afrodescendente nascido em Salvador nos finais do século XIX, como poucos de sua geração, teve fixada a sua memória como personagem vivo em obras amadianas emblemáticas ${ }^{3}$, além de se tornar patrono do único teatro comunitário existente no Pelourinho, ponto turístico de Salvador reconhecido pela UNESCO como Patrimônio Cultural e Paisagístico da Humanidade.

A publicação de biografias autorizadas e não autorizadas sempre encontrou um público de leitores ávidos pela vida alheia. Nessa perspectiva, algumas personalidades da sociedade brasileira tiveram a sua trajetória de vida transformada em livro. Ao que se sabe,

2 A série de entrevistas cedidas pelo empresário e líder religioso Miguel Santana foi organizada pelo sociólogo José Guilherme Cunha Castro e permaneceu no arquivo do IPAC até despertar o interesse do Centro de Estudos Orientais (CEAO/UFBA), que em 1996 publicou o documento em formato de livro, intitulado Miguel Santana.

${ }^{3}$ Em pesquisa bibliográfica realizada em 2006, foi possível identificar na vasta literatura de Jorge Amado a figura de Miguel Santana, pelo menos como personagem vivo, no romance Teresa Batista cansada de guerra (1972) e em edições mais recentes do livro Babia de todos os santos: guia de ruas e mistérios (1982). 
o ator Mário Lago (1911-2002), escreveu um livro autobiográfico intitulado Na rolança do tempo (1977), muito embora tivesse demonstrado uma opinião meio contraditória:

Do visto, ouvido e andado são estes apontamentos. Não de tudo, evidentemente, que parte da vida é bagaço. Nem com a preocupação do quando-depois-do-quando. Ou bem se vive sem cuidado de ordem e tempo, ao sabor do tranco e barranco, ou bem se cumpre expediente, fichas que anotem degrau após degrau. (LAGO, 1977, p. 6)

Detentor de um estilo literário conciso e bastante envolvente, Mário Lago teria a sua autobiografia transformada em verdadeiro best-seller em curto espaço de tempo. Por outro lado, cidadãos comuns como a dona de casa Cidália Fernandes Souza (1937), ao completar setenta anos de vida teve a iniciativa de alavancar um projeto editorial autofinanciado e publicar um opúsculo sob o título: Eu e minha família (2010). Não sendo personalidade como Mário Lago, nem amparada por editora de prestígio nacional, enfrentaria as barreiras naturais de permanecer em certo nível de anonimato literário.

É possível encontrar um sem número de relatos autobiográficos escritos aguardando quem lhe dedique tempo no penoso processo intelectual de leitura, transcrição e reescrita. Não é tarefa fácil decifrar textos manuscritos elaborados por autores semianalfabetos já em idade avançada, com ideias truncadas e com naturais lapsos de memória. Ao lado da dificuldade de leitura dos textos o profissional encontrará desafios crescentes nas tarefas de transcrição e reescrita, seguidos da necessária contextualização histórica e social. No caso de Miguel Santana, os resultados obtidos dependeram da aplicação de questionários previamente elaborados por sociólogos e com objetivos delimitados pela pesquisa. Embora extrapolados pelo entrevistado e, por isso mesmo, tornando-se bastante abrangentes, teriam sido enriquecidos posteriormente com informações de cunho histórico e socioantropológico. Por sua vez, o relato memorialístico de Francisco Catarino teria surgido de iniciativa pessoal e não encontrou de imediato uma destinação institucional nem aproveitamento literário por algum escritor de plantão. Ficaria algumas décadas retido sob a guarda da filha Dalva Araújo em seguida seria compartilhado com o neto Marcos Santana, 
cumprindo os estágios de incubação até se impor como um legado literário de um ancestral familiar que deveria sair do anonimato e atingir o alvo de consumação: os descendentes contemporâneos e de gerações futuras.

\section{Região Sul da Bahia: contextualização histórica e literária}

O município de Ilhéus com o seu porto e, sobretudo, com a generosa produção de cacau redirecionaria o olhar do Estado para toda a região sul indistintamente, e a terra mãe do Brasil reaparece apoiada na força de suas riquezas naturais e da sua gente bravia. No bojo desse longo processo de afirmação política da região cacaueira surgiria uma infinidade de talentos literários que com o passar do tempo desenvolveriam a excepcional capacidade de transformar em romances, em poesia e em cordel aspectos da experiência humana de uma gente muito peculiar nascida em uma terra fértil produtora e reprodutora de bens.

A região Sul da Bahia mais recentemente recebeu o tratamento publicitário do governo estadual de “Terra Mãe do Brasil”. É possível estabelecer alguma relação de superioridade se colocada em paralelo com o que foi feito desde 2012 com a prefeitura da capital, que adotou o tratamento publicitário "Primeira Capital do Brasil" como lema da administração municipal. Por sua vez, na expressão toponímica “Terra Mãe do Brasil” adotada desde 2014, pelo do governo estadual está implícita uma referência histórica que antecede o reconhecimento da cidade de São Salvador da Bahia como primeira capital do Brasil ${ }^{4}$. Trata-se, portanto, de uma referência à chegada da esquadra portuguesa comandada por Pedro Álvares Cabral em Porto Seguro no ano de 1500, data de inauguração da Terra Brasilis. O governo estadual também está sediado na capital, mas buscou amparo publicitário em um acontecimento histórico inaugural da nação brasileira, portanto, politicamente

\footnotetext{
${ }^{4}$ Fundada por Tomé de Souza em 1549, a cidade de São Salvador da Bahia passaria a exercer a função administrativa de Capital do Vice-Reino até 1863, quando o prestigioso título foi transferido para a cidade de São Sebastião do Rio de Janeiro.
} 
mais forte e institucionalmente superior. No decorrer da administração colonial outras regiões ocupariam posições estratégicas e ganhariam prestígio econômico, cultural e religioso. Foi o que aconteceu com o recôncavo baiano e com as ilhas, que estão situados bem próximos do porto de Salvador.

A mesma terra que produziu o cobiçado fruto do cacau como riqueza natural também conseguiria gerar seres capazes de produzir literatura multiforme. Seja em escala editorial volumosa e abrangente, seja em série limitada do ponto de vista regional ou enfeixada pelo caráter do anonimato involuntário.

É indiscutível a produção literária que se originou em todo o desenrolar do século XX nessa região que é o berço do Brasil. Enfeixada sob a denominação de "literatura grapiúna”, nela estão inseridas produções romanescas e poéticas de vultos com reconhecimento nacional e internacional e nela também pode ser inserida de forma inclusiva e abrangente uma produção literária memorialística bastante singular ${ }^{5}$. Assim pode acontecer com o "Livro de vovô", um relato autobiográfico, um manuscrito inédito que narra as peripécias de um patriarca nascido em Ilhéus e que teve uma trajetória marcada por conquistas sociais bem-sucedidas e por vários infortúnios, porém com uma invejável capacidade de superação. Guardado entre objetos pessoais e fotografias, ficaria algumas décadas no mais completo esquecimento. Certamente esperaria o tempo oportuno para tornar-se público como verdadeiro testamento. O documento literário foi elaborado com as próprias mãos de quem acreditava que seus desejos seriam concretizados após o falecimento. Constituído de ideias e crenças, também pode ser considerado um inventário familiar capaz de revelar aspectos sociais remotos do que viria a ser propagado de forma genérica na expressão "grapiúna":

Eu sou do sul da Bahia

Município de Itabuna

Nascido no município de Ilhéus

${ }^{5}$ Cf. Dicionário de autores baianos, 2006. COSTA, 1959; AMADO, 1987; ADONIAS FILHO, 1981 e MEDAUAR, 2016; produziram obras temáticas referenciais sobre a região e integram a plêiade de autores que legitimaram a chamada "literatura grapiúna". 
Verdadeiro grapiúna. ${ }^{6}$

Seu Francisco Catarino se apresenta como "Verdadeiro Grapiúna”. Ele é simultaneamente personagem protagonista e narrador da história contada em versos. Também se mostra detentor de um estilo literário no qual predomina a oralidade. Poderia ter se tornado personagem de alguns desses romances que foram surgindo a partir da década de 1930. Poderia, igualmente, integrar as produções poéticas que tão bem retratam a paisagem local, formada por belas praias e por uma vegetação rica e produtiva.

O contato com o texto do velho Chico representa o mesmo que acontece quando a se é criança e ouve histórias sem pé nem cabeça, mas se acredita, imagina, fantasia e viaja no tempo e no espaço. No caso de quem não o conheceu e nem sabia das suas artimanhas, dos seus segredos e da sua forma de ver o mundo ao entrar em contato com uma realidade histórica, ancestral e familiar, pode transformar-se em um aprendizado humano e intelectual, possivelmente estabelecido pela via literária.

A vida desse homem sertanejo revela aos leitores traços de um ambiente social marcado por valores morais que remetem ao Brasil Colônia. A narrativa dele traduz esse ambiente cultural. Trata-se, portanto, de um relato memorialístico dirigido aos parentes. Não fosse um "romanço", expressão cunhada pelo autor, seria uma novela ou um conto de fadas.

Parece que a região grapiúna ainda é pouco conhecida em suas estratificações sociais. Nas muitas localidades que percorreu em busca de abrigo encontrou uma gente hospitaleira entre criaturas imaginárias e fantasmagóricas. Então, é possível que a história de vida de Francisco Catarino tivesse inspirado alguns daqueles cordelistas que encontram no desatino das pessoas comuns os elementos literários que despertam a imaginação criativa. Ingredientes desse tipo servem de enredo para uma narrativa com sucesso garantido, podendo ser contada em aglomerações semanais das tradicionais feiras do interior baiano ou

${ }^{6}$ Fragmento do Cordel de memórias de Francisco Catarino. 
mesmo cantada em quermesses paroquiais, que costumam acontecer durante as celebrações de santos padroeiros.

\section{Quem é esse tal Francisco: "verdadeiro grapiúna"?7}

Francisco Catarino Alves de Souza, Patriarca de uma extensa família grapiúna, cuja origem simbólica coincide com o nascimento dele às margens do Rio Almada no dia 9 de março de 1901. A sua trajetória terrestre seguiria o curso natural das águas, e suas sementes, transformadas em brotos de árvores frondosas, iriam se espalhando por outras regiões da velha Bahia, indo alcançar os rincões mais longínquos do território nacional.

Do município de Ilhéus onde nasceu guardaria breves recordações da infância e juventude. O moço Chico Catarino sempre esteve amparado no ambiente familiar até surgir em sua mente um plano de casamento com a jovem enamorada Maria Izabel.

Nada teria chegado às suas mãos sem o esforço da conquista. Assim teria acontecido com o enlace matrimonial nos idos de 1923. O evento das núpcias trouxe para ele a possibilidade de convívio esponsal intenso de felicidade e encantamento. Duraria o tempo suficiente para a geração de filhos e filhas que perpetuariam o seu nome pela sucessiva prole que surgia ano após ano.

Reconhecidamente vocacionado para a vida matrimonial, ensejaria o surgimento de novas experiências com o intuito de recuperar os dias felizes que marcaram as primeiras núpcias. Após o falecimento de Maria Izabel de Souza em 1935, conheceu a Raimunda Barbosa e em pouco tempo decorrido casou-se com ela no ano de 1938. Desse novo consórcio teve duas filhas e um filho.

\footnotetext{
${ }^{7}$ A biografia desse cidadão grapiúna tem sido alvo de pesquisas do Centro de Estudos Miguel Santana desde 2012. Ao que se sabe, ele que teve destacada atuação política como Agente Arrecadador no distrito de Coquinhos. Uma análise mais profunda pode revelar dados socioantropológicos definidores de classes subalternas que em determinado período desempenharam papéis administrativos em microrregiões da Bahia.
} 


\section{Conclusão}

Ninguém nasce sem que duas pessoas de sexo oposto se encontrem, se amem e estabeleçam uma relação esponsal. Assim teria acontecido com os pais de Francisco e Izabel. Assim aconteceu com os pais de minha mãe e com os pais de meu pai, que por coincidência se casaram no mesmo ano: 1923. Teria sido amor à primeira vista? Teria sido encantamento entre dois jovens enamorados?

Para muitas pessoas o sentido da vida se apresenta sob as diversas formas: realização profissional, amorosa, artística, sacerdotal etc. Para o jovem Francisco Catarino a vida só passaria a ter real sentido quando ele se encontrou com uma jovem chamada Maria Izabel e dela enamorou-se de uma forma extraordinária e bela.

É fácil perceber que ele passou a nutrir um sentimento tão forte, puro e sadio que não hesitou em candidatar-se a ocupar o coração da inexperiente moça casadoira. Francisco sabia no seu interior que Izabel havia nascido para ele e ele para Izabel. Tratou logo de submeter os seus propósitos aos pais dela. Aguardou o tempo necessário para receber a resposta, cumprindo rigorosamente as formalidades da época e logrou o êxito esperado: obteve o consentimento dos pais dela para iniciar o namoro respeitoso.

Francisco sonhava em casar-se logo com Izabel e ter como certo o convívio diário com a sua amada. Esperou o tempo suficiente até chegar o dia 8 de julho de 1923, data escolhida para a união definitiva em matrimônio realizado na Catedral de Água Preta com todas as pompas que a ocasião exigia. Francisco era o homem mais feliz do mundo, estava realizando o sonho de sua vida até ali. Alcançara a felicidade plena, conquistara o amor de sua vida, cuja realização lhe daria a possibilidade de perpetuação de seu nome na face da terra.

Amor, ternura, paixão, cumplicidade, complementaridade e muitas outras palavras poéticas poderiam definir o casamento de Francisco e Izabel. É impossível enumerar os qualificativos para essa união esponsal sem submetê-la ao gênero do conto de fadas. Desse enlace matrimonial nasceriam os primeiros filhos e as primeiras filhas. 
Interrompida a harmonia do lar pelo acometimento súbito de uma enfermidade, viria, paulatinamente, a completa desagregação familiar em 1935, com o falecimento precoce da mulher mais amada do mundo. A relação esponsal estabelecida entre Francisco e Izabel chegara a um termo de forma dramática. Francisco teve que encontrar forças para conduzir o seu destino de pai com uma atenção especial aos filhos que ficaram órfãos maternos ainda em tenra idade.

Ciente de que a felicidade pessoal estava no casamento, logo tratou de casar-se em segundas núpcias, contraindo matrimônio dessa vez com Raimunda Barbosa em 18 de outubro de 1938, na Igreja Matriz de Pimenteira.

Qual teria sido o motivo de um patriarca como Francisco Catarino deixar registradas para a posteridade as experiências mais marcantes de sua trajetória existencial? Os casamentos que teve e as gerações de filhos e filhas representam a realização pessoal mais profunda. Também representam a afirmação de uma vocação que se concretizou entre muitos percalços. Por fim, garantiriam a perpetuação do seu nome como força vital que se renova e se multiplica em cada descendente, década após década, prolongando indefinidamente a sua patrilinearidade. $\mathrm{O}$ fato é que seu esforço em escrever uma autobiografia não ficou em vão. Assim como traços da sua memória, transformados em versos de cordel, não foram totalmente esquecidos. Ficariam um longo período sob a custódia de sua filha Dalva Araújo, que em 1998 teve uma inspiração para compartilhar o importante documento literário com o neto Marcos Santana. Após 20 anos desse primeiro compartilhamento do material autobiográfico do insigne ancestral grapiúna, tendo passado por minucioso processo de reescrita, conhece agora o tempo favorável de compartilhamento entre os leitores mais variados possíveis. Alcança os filhos que ainda sobrevivem e se estende aos netos, bisnetos, trinetos e demais familiares. 


\title{
CORDEL OF MEMORIES BY FRANCISCO CATARINO: TRUE GRAPIÚNA
}

\begin{abstract}
This article entitled "Cordel of memories by Francisco Catarino: true grapiúna" represents an intelectual effort to give visibility to the autobiographical account of the citizen Francisco Catarino Alves de Souza, born in the city of Ilhéus on March 9, 1901, on the border of Rio Almada. The manuscript left by him comes to light after remaining five decades in the most complete anonymity. A judicious process of reading, transcription and rewriting would give rise to a possible publication. On the other hand, the full awareness of citizenship would have inspired the author to identify himself in the text as "true grapiuna" and this self-affirmation identify served as the guiding thread for the development of this article in dialogue with other literary voices that represent the southern of Bahia naturally.
\end{abstract}

KEYWORDS: Authobiography; Cordel; Memory; Literature.

\section{REFERÊNCIAS}

ADONIAS FILHO. Auto dos Ilhéus. Rio de Janeiro: Civilização Brasileira, 1981.

AMADO, JORGE. Tenda dos milagres. São Paulo: Martins Fontes, 1969.

. Teresa Batista cansada de guerra. Rio de Janeiro: Record, 1972.

Babia de Todos os Santos: guia de ruas e mistérios. Rio de Janeiro: Record, 1982.

. O menino grapiúna. Rio de Janeiro: Editora Record, 1987.

BAHIA. Governo do Estado / Secretaria de Cultura e Turismo. Dicionário de autores baianos. Salvador: Secretaria de Cultura e Turismo, 2006.

BARROS, Francisco Borges de. Memória do município de Ilhéus. $3^{\text {a }}$ edição. Ilhéus: Editus / Fundação Cultural de Ilhéus, 2004.

BRANDÃO, Arthur \& ROSÁRIO, Milton. Estórias da história de Ilhéus. Ilhéus: Edições SBS Ltda., 1970.

CASTRO, José Guilherme Cunha. Miguel Santana. Salvador: EDUFBA, 1996.

COSTA, Sosígenes. Obra poética. Rio de Janeiro: Ed. Leitura, 1959.

HEINE, Maria Luiza. Passeio por São Jorge dos Ilhéus. Salvador: Agora Editora Gráfica, 2003.

LAGO, Mário. Na rolança do tempo. $3^{\text {a }}$ edição. Rio de Janeiro: Civilização Brasileira, 1977. Col. Tempo e Contratempo, v. 4.

MEDAUAR, Jorge. Sobreviventes de Água Preta. Salvador: ALBA, 2016.

SALES, Fernando. Declaração de bem querer a São Jorge dos Ilhéus. São Paulo: GRD, 1981a.

Col. Grapiúna, v. 3.

. Memória de Ilhéus: edição comemorativa do centenário de sua elevação a cidade.

São Paulo: GRD / Prefeitura Municipal de Ilhéus, 1981b.

SOUB, José Nazal Pacheco. Minha Ilhéus: fotografias do século XX e um pouco de nossa história. Itabuna: Agora Editora Gráfica, 2005. 
SOUZA, Cidália Fernandes. Eu e minha família. Medeiros Neto: Edição da autora, 2010.

Recebido em: 31/05/2015.

Aprovado em: 16/07/2018.

E agora caros parentes

Minha vida vou descrever

Em romanço tão penoso

Como poderia vencer

Só com o Pai Celestial

Que poderia me ajudar

Hoje eu ter o que escrever

Esta história que conto

Faz até gente chorar

Quem ler este começo

Deseja ver findar

Foi um sofrimento tão triste

Que nunca mais existe

Que não pode se tolerar

Eu nasci em 1901

No dia 9 de março

Criado por pai e mãe

Para eles era um disfarço

Consultava a sua vida

Sem vexame e distraída

Que poderá passar em palácio

E assim fui um bom filho

De natureza excelente

E fiz uma fugida 
E sempre obediente

Minha patroa me aconselhou

Senhor Francisco, o senhor errou

Não seja tão violento

E por isto meu companheiro

Meu pai veio à minha procura

Eu posso acompanhar

Que este choque atura

Pode voltar a mesma instrução

Comigo e meus irmãos

Transformar em muita feiura

Quando assim começou

Eu peguei a planejar

Pois tinha uma moça vizinha

Eu peguei a reparar

Peguei a fazer os meus planos

Será que nestes cinco anos

Eu poderei me casar?

Foi em fevereiro daquele ano

Eu com vinte e dois de idade

Comecei a querer bem

Com toda casualidade

Consultei a minha consciência que existia

Existência que não era falsidade

Mandei falar sobre o casamento

Por pessoas das amizades

Pois nesta época

Noivo não tinha liberdade

Havia muita cerimônia

Para o que tinha vergonha

Era pura sinceridade

E por isto levei dois meses

Para receber a resposta

Um bocado destes parentes zangados

Quando souberam da proposta

Eu esperei o chefe da família

Dar o valor que eu merecia

Para ele dar uma resposta 
Então depois de dois anos

Foi nosso enlace resolvido

Eu dei-lhe de mulher e esposo

Ela de esposa e marido

Foi uma hora tão santa

Que os anjos cantam no paraíso

Conseguimos cinco filhos neste feliz casal

Vivemos doze anos e sete meses

Sem uma marca no sentar

$\mathrm{O}$ que queria que era noite ou dia

As coisas só eram iguais

No período deste tempo

A tirana morte a levou

Esse meu sofrimento

Tão penoso que corta dor

Eu quando via aquele estado

Eu lembro do amor passado

O coração me cortava de dor

Depois do sepultamento

Cinco filhos que ficaram

Roguei a Deus nas alturas

Como poderia dar um amparo

Não imaginava carestia

Pois isto ainda não tinha

E nada existia caro

Foi com um ano depois

Eu mudei desta cidade

Indo para uma zona

Que tinha algumas amizades

$\mathrm{E}$ ali fiquei sete anos

Foram desiguais os meus planos

Que houve muita falsidade

Resultado desta chegada

Agora eu vou contar

Levei pouco dinheiro

Mas com roupa e novo ânimo 
Se não fosse a grande usura

O que é não se dura

Eu havia de prosperar

Ali eu peguei a trabalhar

De vez em quando uma festinha

E também muita arte

Foi fazer uma sombrinha

E também, pois este meio

Eu sendo muito feio

Arranjei uma moreninha

Arranjei esta morena

$\mathrm{Na}$ família dos Barbosa

Enquanto o tempo do sogro

Uma vida saborosa

Porque o temente faleceu

Fizeram de mim um judeu

Me deram remada rigorosa

Eu possuía casas de telhas

Roça e mangues de aluguel

Todo esforço que fazia

Não podia tomar pé

Já com 2 filhas para criar

Este precisa amparar

Um é homem, outra é mulher

Trabalhei muito nesta fazenda

Para fazer a independência

Quanto mais trabalhava

Menos tinha a crença

E eu vou tão apertado

Quase me vou fuzilado

Igual à massa na prensa

Cheguei a ir à cadeia

Pelo que me pertencia

O mau vizinho me perseguindo

Quer noite ou dia

Pois só tinha desejo

De me ver na cama de percevejo

Com a barriga vazia 
Eu não podia me conformar

Com tantas derrotas sofridas

Pensando que com toda calma

Eu podia vencer na vida

Todos meus foram errados

Neste tempo amargurado

$\mathrm{E}$ todas despesas perdidas

Agora vou contar

O resultado da Moreninha

Resolveu se prostituir

De que dar direito no que tinha

Eu tive de me conformar

E a vida consolar

Meu Deus, que sorte a minha

Este meu filho

Já estava bem criado

Vivia por conta própria

E tinha bom ordenado

Eu mudei de condição

Fui me embora para o sertão

Para viver mais sossegado

O que possuía deixei

Nada pude vender

Dei por um terço da metade

Para de tudo não perder

Os meus feitos deixados atrás

Eu para lá não olhei mais

Deu para junto enriquecer

Foi com 43 anos de idade

Que estas coisas me surgiram

Vou mudar para outra cidade

Para ver que vida adquiro

Que aqui onde moro

Onde trabalho e choro

Nada mais eu aspiro

Me mudei para uma cidade 
Onde o povo já me conhecia

Para ver se por ali

Arranjava simpatia

Não cheguei desprevenido

Pois não andava perdido

Que ainda levei duas filhas

Então peguei a trabalhar

$\mathrm{E}$ as coisas a me favorecer

Sei que aqui agora

Eu vou me desenvolver

De acordo o que Deus quiser

Esta é minha fé

Tudo hei de vencer

Ali trabalhei 7 anos

Fazendo 17 casinhas

Progresso na vilazinha

$\mathrm{O}$ único a me lembrar

Dos possuídos que tinha

$O$ povo que morava ali

Não precisa deste aqui

Me tratavam carinhosamente

De doce, queijo e galinha

O povo até gostava de ver meu progresso

Não está muito bom para mim

Que me estava avesso

Saindo de um para outro estado

Este é um homem honrado

De quem nós temos interesse

Com o povo eu fui trabalhar

E eu trabalhei por eles

Foi quando entrei na Política

E muito eu lhes ajudei

Quando foi na minha saída

A localidade toda sentida

Que não temos outro como aquele

Que cargo foi meu

Que deixava tanta dor 
A função foi tão pequena

Que no entanto se passou

Simplesmente deu prazer

Todos queriam ver

$\mathrm{O}$ seu agente arrecadador

Foi quando na eleição

A política estremeceu

Quem estava debaixo subiu

Quem estava em cima perdeu

Quando perguntaram o meu nome

Quem votou em mim: 500 homens

$\mathrm{E}$ nada disso valeu

Eu me desgostei da Política

E também dos homens da Lei

Pois não me deram direito

Tanto que trabalhei

Ver companheiro sofrer

$\mathrm{E}$ eu sem poder proteger

$\mathrm{E}$ por isto me desgostei

Arrumei a minha bagagem

Ali não quis ficar

Os companheiros me aconselharam

O senhor não deve se retirar

O senhor sabe se conformar

O tempo é ruim para quem morre

Até nossa política voltar

Eu não quis atender

Tive uma desconfiança

Tudo com a morte se acaba

E tudo com a vida se alcança

Desta vou bater

Se Deus me proteger

$\mathrm{Na}$ vila de Nova Esperança

Chegando em Nova Esperança

Para vila que regressei

Logo com poucos dias

Bons amigos eu encontrei 
Demorando por ali meus dias

Logo tive simpatia

Talvez aqui me arrumarei

Eu cheguei naquela terra

Sempre a negociar

O povo por ali

Pegaram a me reparar

Um dia chegaram a mim

Sem saber de onde eu vim

Trataram a me perguntar

Meu velho, de onde é o senhor?

Eu quero lhe conhecer

Sabendo da sua biografia

Poderemos lhe proteger

Só assim podemos dar dinheiro

Crédito e animais

$\mathrm{O}$ valor que merecer

Eu sou do sul da Bahia

Município de Itabuna

Nascido no município de Ilhéus

Verdadeiro grapiúna

Venho mudando

Para outras cidades

Para aumentar amizades

Que as condições já repugnam

Chegando aqui nesta casa

Junto com velhos mineiros

As coisas não foram melhores

Cheguei derradeiro

Vou tomar novos planos

Se eu ficar aqui 10 anos

Vou ganhar muito dinheiro

Então eu continuei a trabalhar

Aí eu fiquei pensando

Em continuar a trabalhar

E os que fingiram saber

Pegaram a me atrapalhar 
Me sopraram uma macumba

Feita com sapo sunga

Que saí sem acertar

Foi em junho de 1952

Eu desci do alto sertão

Vim à minha terra querida

Onde deixei os meus patrões

Onde me davam confiança

Chegando de Nova Esperança

Nos tempos das eleições

Com a idade que tenho

E tanto tempo perdido

Pedi ao meu Deus

Para não ser vencido

Ele me clareasse o caminho

Assim como vivo sozinho

Para que não seja vencido

Neste tempo me assossegado

Porque não tenho mulher

Pois já tinha lutado diversas

E não podia tomar pé

Vou ficar um certo tempo

Logo que já tenho exemplo

Ver o que é, o que é

Quando eu segui do sertão

Fui para uma terra sem amizades

O restante do saldo que tinha

Deixei em propriedades

Aguardando fazer bons negócios

Quando houvesse facilidades

Deixei a arte de carpina

E fui trabalhar em um armazém

Só com a cara e a coragem

No bolso nem dois vinténs

Fiquei consultando comigo

Meu Deus, será um castigo?

Poderá ser para meu bem? 
Fui trabalhar em um comércio próprio

Pois tinha merecimento

As firmas me confiaram

Que tinha merecimento

Sendo pai de um filho formado

Que tem todo consentimento

Foi em uma fazenda na roça

Eu fui me estabelecer

Tudo junto dali

Já era de me conhecer

Trabalhando muito na vida

Com duas filhas queridas

$\mathrm{O}$ que poderá me suceder?

FIM. 